\title{
EXPERIENCIA DE EXTENSIÓN UNIVERSITARIA EN HUERTAS COMUNITARIAS DE ORGANIZACIONES BARRIALES
}

\section{Universitary extensión experiences in vegetable gardens from social organizations}

\author{
Paladino, Ileana R. ${ }^{1-2}$; Sokolowski, Ana C. ${ }^{2}$; Navas, Mauro²; Gagey, María C. ${ }^{2}$; Barrios, \\ Mónica B. ${ }^{2}$; Rodríguez, Hernán A. ${ }^{2}$; Wolski, José E. ${ }^{2}$ \\ ${ }^{1}$ CEI GORINA-INTA AMBA. Calle 501 entre 147 y 149, Gorina, La Plata; \\ ${ }^{2}$ Facultad de Ciencias Agrarias, Universidad Nacional de Lomas de Zamora. \\ E-mail: paladino.ileana@inta.gob.ar
}

\section{RESUMEN}

Con el crecimiento poblacional de los últimos años la agricultura urbana ha alcanzado un gran desarrollo. En el caso de Argentina, algunos movimientos de trabajadores, vienen desarrollando huertas comunitarias bajo sistemas agroecológicos dentro de barrios populares. La producción se realiza sobre suelos urbanos, cuyas características naturales están modificadas. No existe información previa de estos suelos ni de los efectos del sistema agroecológico, lo cual es importante para detectar problemas y adecuarse a la situación local. La educación y los programas de extensión colaboran con este fin y los talleres participativos, permiten una reflexión colectiva de los actores comprometidos. En este sentido, el objetivo del trabajo fue generar espacios de vinculación, mutuo conocimiento e intercambio y así contribuir a la mejora en el funcionamiento de los sistemas productivos comunitarios locales sobre suelos urbanos. Se realizaron dos talleres en huertas comunitarias dentro de dos barrios populares de La Plata. En el marco de los talleres se realizó el diagnóstico del estado de salud de los suelos, se analizó el agua y surgieron propuestas de manejo consensuadas para mejorar los sistemas productivos existentes. La experiencia facilitó la generación de espacios de intercambio y mutuo conocimiento entre la comunidad educativa y los huerteros. También, se pudieron visibilizar las necesidades de quienes trabajan en las huertas y las temáticas que requieren una mayor promoción en futuros programas de extensión. Uno de los mayores desafíos que se presentan hacia el futuro es aumentar la asistencia e intervención de los huerteros en los espacios de vinculación.

Palabras clave: agroecología, talleres participativos, suelos urbanos, horticultura urbana.

\begin{abstract}
With the population growth in the last years, urban agriculture has had a great development. In Argentina, some workers' movements have been developing community vegetable gardens under agroecological systems in working-class neighbourhoods. The production is carried out on urban soils, whose natural characteristics have been modified. There is no previous information either of these soils or about effects of the agroecological system. This information is important to detect problems and to adapt the management to the local situation. Education and extension programs help to pursue this aim and participatory workshops allow committed participants to reflect collaboratively. In this sense, the aim of this work was to foster equity, mutual understanding and exchanges so as to contribute to the improvement of local community production systems functioning on urban soils. Two workshops on community vegetable gardens were held in two working-class neighbourhoods from La Plata. In these workshops a diagnosis of soil health was carried out and also water was analysed. In addition to this, proposal agreements emerged to improve the existing production systems. The experience has generated exchanges and mutual understanding between the educational community and vegetable garden keepers. Also, vegetable garden keepers' necessities and topics that require greater attention in future extension programs were highlighted. One of the greatest challenges for the future is to increase assistance and intervention of vegetable garden keepers in community spaces.
\end{abstract}

Key Words: agroecology, participatory workshops, urban soils, urban horticulture.

Recibido: 08/jun/2020. Aceptado: 27/jul/2020 


\section{INTRODUCCIÓN}

La agricultura urbana existe en el mundo desde tiempos inmemoriales, pero durante el siglo XX, con el incremento de la población dentro de las ciudades, alcanzó un gran desarrollo pues permitió resolver el problema del deterioro en la calidad de vida y la seguridad alimentaria (Hernández, 2006).

Por agricultura urbana se entiende a la producción de alimentos en pequeña escala y dispersa, dentro de los confines de las ciudades, en patios, terrazas, huertos comunitarios y espacios públicos libres (FAO, 1996). Esta producción urbana, es más diversificada, más orgánica y con nuevos agricultores (Pino, 2003) ya que es llevada adelante por sus propios habitantes, sobre ecosistemas urbanos, tratando de mantener la sostenibilidad (económica, social y ambiental). Sus productos se destinan a satisfacer las demandas alimentarias y otras necesidades de la población y cuenta, en su carácter de movimiento, con apoyo y conducción organizada de gobiernos locales u otros actores (Urbes, 2005).

En Argentina, algunos movimientos de trabajadores, como el Frente de Organizaciones en Lucha (FOL), vienen impulsando la producción, de manera cooperativa, en huertas comunitarias dentro de barrios populares que aun constituyen asentamientos informales precarios (Rodríguez Tarducci, 2018). Gran parte de la producción se destina a comedores barriales o consumo propio. De este modo, las huertas constituyen un factor importante para mejorar la alimentación de sectores de la población con dificultades para obtener alimentos, especialmente frescos, y que usualmente sólo ingieren carbohidratos y comida enlatada. Esto demuestra que las huertas comunitarias pueden contribuir de forma clara a la seguridad alimentaria de distintas maneras ya que, aumentan la cantidad de alimentos disponibles para los pobres de las zonas urbanas y la frescura de los mismos e incrementa la variedad de los productos y su valor nutritivo (Chavarrías, 2005). A su vez, estos espacios sirven como referencia para todos los habitantes del barrio fomentando relaciones humanas constructivas y fortaleciendo vínculos entre vecinos y vecinas. De esa manera, se generan barrios autosustentables con menos generación de basura, ciclado de nutrientes, relaciones de intercambio diferentes, y más comida saludable (FOL, 2019).

Un problema existente en las huertas de barrios populares es que las mismas se desarrollan sobre suelos cuyas características naturales se encuentran modificadas. Los suelos urbanos también son llamados suelos antrópicos, ya que suelen estar disturbados debido a las actividades humanas que existen a su alrededor como el mezclado, importación y exportación de materiales (De Kimpe y Morel, 2000; Pereyra et. al, 2017) e incluso pueden estar completamente desarrollados a partir de material exógeno trasportado desde lugares remotos (Craul, 1999). En general, se caracterizan por estar contaminados, compactados y/o sellados, por lo que sus propiedades normalmente no son favorables para el crecimiento de las plantas y por lo tanto, su papel en la producción de alimentos se encuentra comprometido (Lal y Stewart, 2017).

En la ciudad de La Plata existen varios barrios populares donde los vecinos organizados en el FOL vienen cultivando en huertas comunitarias desde hace más de tres años con un enfoque agroecológico. Este sistema se basa en aprovechar los procesos naturales de las interacciones que se producen en una huerta, con el fin de reducir los insumos externos (muchos de ellos potenciales contaminantes) y mejorar la eficiencia biológica de los sistemas de cultivo (Sarandón y Flores, 2014). Además, el enfoque de producción agroecológica propone estrategias de manejo de suelos que pueden contribuir a mejorar las propiedades productivas, más aun en suelos de baja calidad como los urbanos. En la práctica, se trabaja con rotación y asociación de cultivos, no se emplean agroquímicos, se utiliza compost realizado por la propia comunidad a partir de desechos orgánicos domiciliarios y se emplean gran cantidad de plantas aromáticas. En la actualidad, no existe información de suelos a escala de detalle para estos barrios populares, formados íntegramente por suelos antrópicos, y los sitios donde se instalaron las huertas no han sido caracterizados antes de entrar en producción. Asimismo, quienes llevan adelante las huertas, no han analizado los efectos que generó en el suelo antrópico la producción hortícola agroecológica desde su inicio. Por tal motivo, las evaluaciones que se efectúen en el terreno, resultan de vital importancia para detectar problemas y adecuar los sistemas productivos a las situaciones locales (Giuffré et al., 2013).

Está claro que, tanto agricultores como las personas directamente en contacto con el suelo, deben comprender los beneficios de la agroecología y las prácticas de manejo sostenible de la tierra antes de poder aplicarlas. En este sentido, asegurar el suministro de alimentos en las zonas urbanas y proporcionar la información adecuada y capacitación a todos los interesados, es un desafío (Figueroa y Izquierdo, 2002). La educación, los pro- 
gramas de extensión y la promoción de tecnologías adecuadas tienen un papel fundamental en este aspecto. Asimismo, los problemas socio-ambientales en territorios municipales requieren de abordajes procedimentales que involucren la multiplicidad de saberes (científicos-técnicos, políticos y ciudadanos) no solo en el diagnóstico de situaciones problemáticas, sino también en la generación de planes de acción que acoplen capacidades colectivas cognitivas para la potenciación en el logro de la sustentabilidad ambiental. Las estrategias participativas como los talleres de participación constituyen plataformas interactivas que reúnen a los diferentes actores sociales comprometidos en una problemática territorial (Poggi, 2016). En este sentido, el objetivo del presente trabajo fue generar espacios de vinculación, mutuo conocimiento e intercambio y así contribuir a la mejora en el funcionamiento de los sistemas productivos comunitarios locales sobre suelos urbanos.

\section{METODOLOGÍA Y RESULTADOS OBTENIDOS}

La Facultad de Ciencias Agrarias de la Universidad Nacional de Lomas de Zamora (FCA-UNLZ) y el Instituto Nacional de Tecnología Agropecuaria (INTA) comenzaron a trabajar desde el año 2017 con vecinos organizados en el FOL a través de un proyecto de extensión universitaria, aplicando estrategias participativas.

El desarrollo de la experiencia tuvo lugar en dos barrios de La Plata donde se trabaja de manera colectiva en huertas comunitarias: "Altos de San Lorenzo" y "El Carmen” (Figura 1a, b y c). El primero está emplazado sobre un antiguo basural que ha recibido el aporte del arroyo que lo rodea, el cual es un afluente del arroyo Maldonado. El segundo está constituido sobre material removido del fondo del arroyo Maldonado en su tramo final. Las huertas tienen una superficie aproximada de $6 \mathrm{~m}$ x $8 \mathrm{~m}$ en "El Carmen" y de $10 \mathrm{~m}$ x $8 \mathrm{~m}$ en "Altos de San Lorenzo". El agua utilizada para riego y para consumo es de red pero está conducida a través de tuberías precarias que circulan sobre las calles, donde están sometidas a eventuales roturas que constituyen vías de entrada de posibles patógenos y contaminantes.

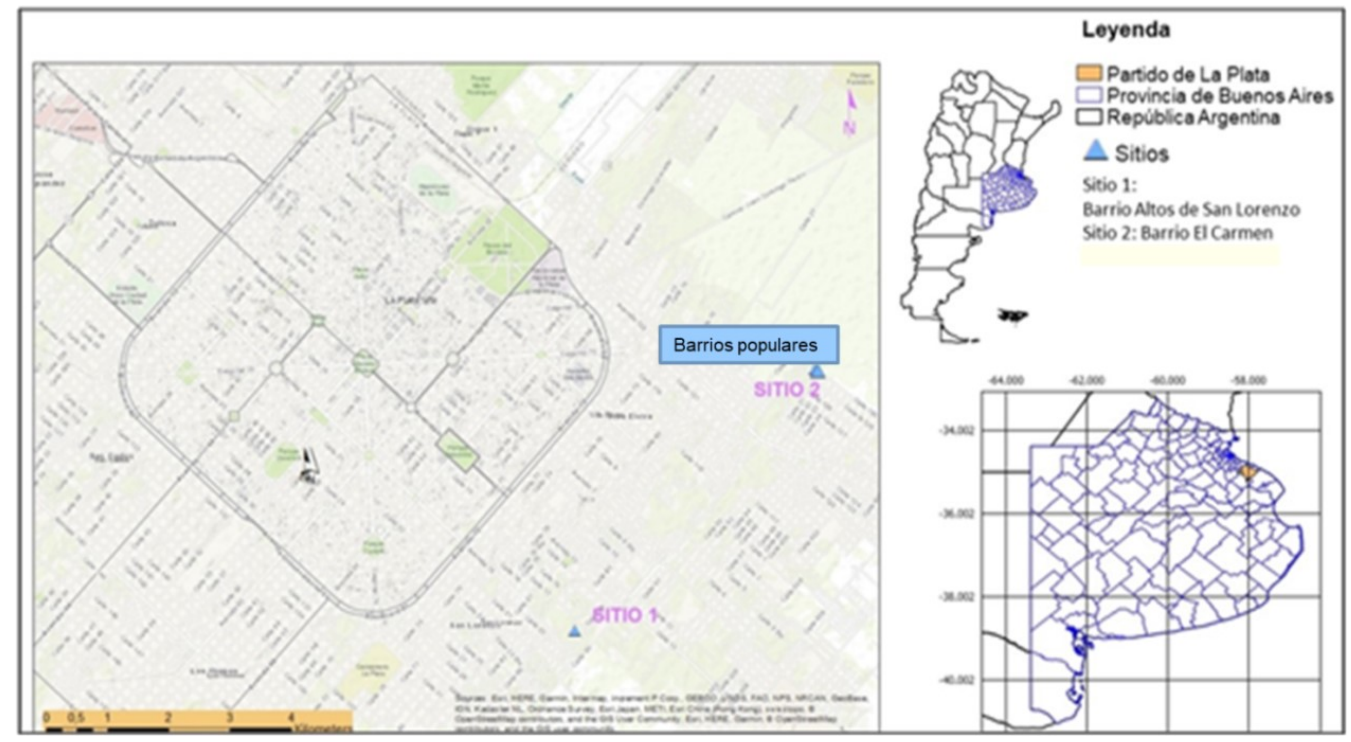

Figura 1a. Ubicación de los barrios populares de La Plata donde se desarrolló la experiencia.

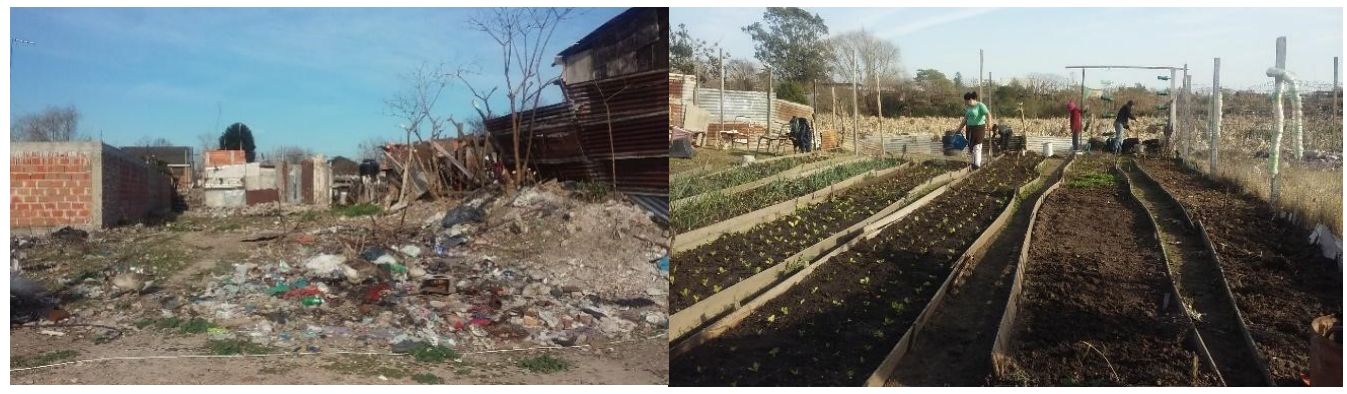

Figura 1b. “Altos de San Lorenzo” entorno y huerta. 


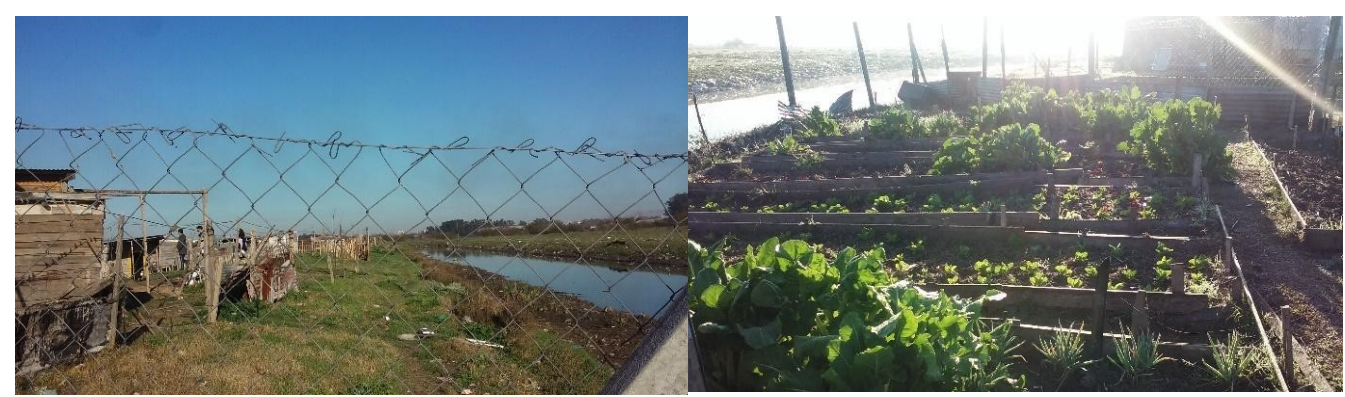

Figura 1c. "El Carmen” entorno y huerta.

El desarrollo de la experiencia se llevó a cabo mediante dos talleres:

\section{Primer taller}

En ambos barrios se realizaron determinaciones de propiedades químicas y físicas, tanto en los suelos urbanos sin trabajar como en los suelos donde se desarrollan las huertas. Dichas determinaciones se realizaron en el marco de un taller teórico-práctico en el que participaron docentes del grupo Suelos y ayudantes alumnos de la FCA-UNLZ, investigadores de INTA y vecinos y vecinas huerteros de los barrios. En la instancia teórica (Figura 2) se realizó una introducción a la noción de calidad de suelos e indicadores de calidad de suelos y se explicó cómo utilizar el instrumental para las determinaciones de indicadores a campo. También se dieron algunas herramientas teóricas para el muestreo de suelos como ser la importancia del correcto muestreo para la obtención de datos confiables, tipo y cantidad de muestras a tomar, época y frecuencia de muestreo, localización y profundidad de muestreo, tipos de muestreo, elementos necesarios para el muestreo, acondicionamiento de la muestra. Asimismo, se explicó cómo realizar un correcto muestreo de agua.

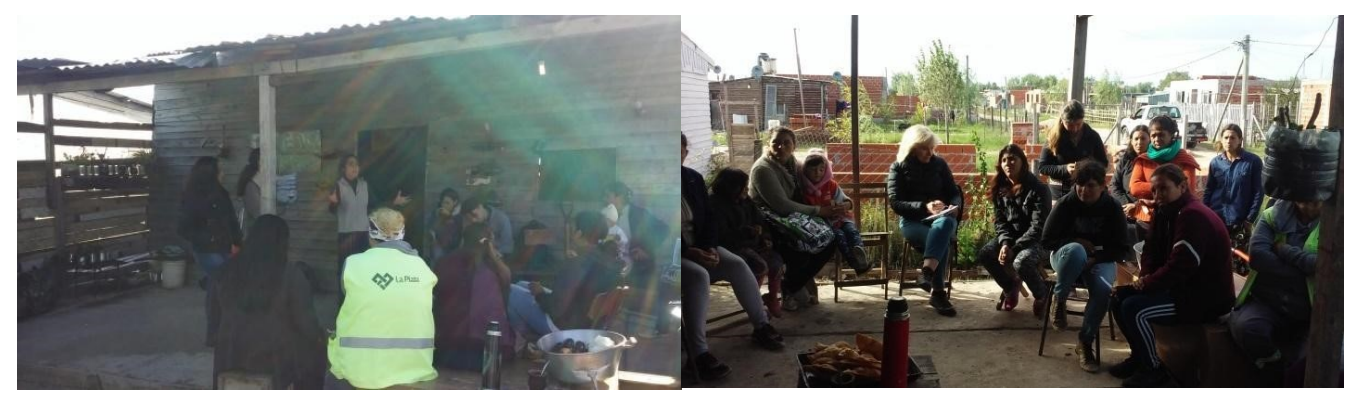

Figura 2. Instancia teórica: Explicación de conceptos: calidad de suelo, indicadores, muestreo de suelos.

Luego, se procedió a la instancia práctica (Figura 3) donde todos los participantes realizaron las determinaciones de los indicadores de calidad de suelos en las huertas de "El Carmen" utilizando el instrumental aportado por la FCA-UNLZ y practicaron la extracción de muestras. Entre las determinaciones realizadas podemos enumerar la densidad aparente por el método del cilindro, la resistencia a la penetración con el penetrómetro de impacto, el muestreo específico para estabilidad estructural y la confección de muestras compuestas de suelo para determinaciones químicas en laboratorio $(\mathrm{pH}$, conductividad eléctrica, nitrógeno total, fósforo extractable y carbono orgánico total). En el agua se determinó nitratos, nitritos, bacteriológico, $\mathrm{pH}$ y conductividad eléctrica. Las determinaciones y muestreos en el barrio "Altos de San Lorenzo", se realizaron también en el marco del taller pero en otra jornada.

Las muestras de suelos fueron analizadas por investigadores y ayudantes en el laboratorio de suelos de la FCA-UNLZ. Para el análisis de las muestras de agua se trabajó en cooperación con técnicos de la Universidad Nacional de Lanús. Los resultados de las determinaciones a campo y en laboratorio, fueron analizados estadísticamente por el grupo Suelos de la FCA-UNLZ (publicados en Paladino et al., 2019). 


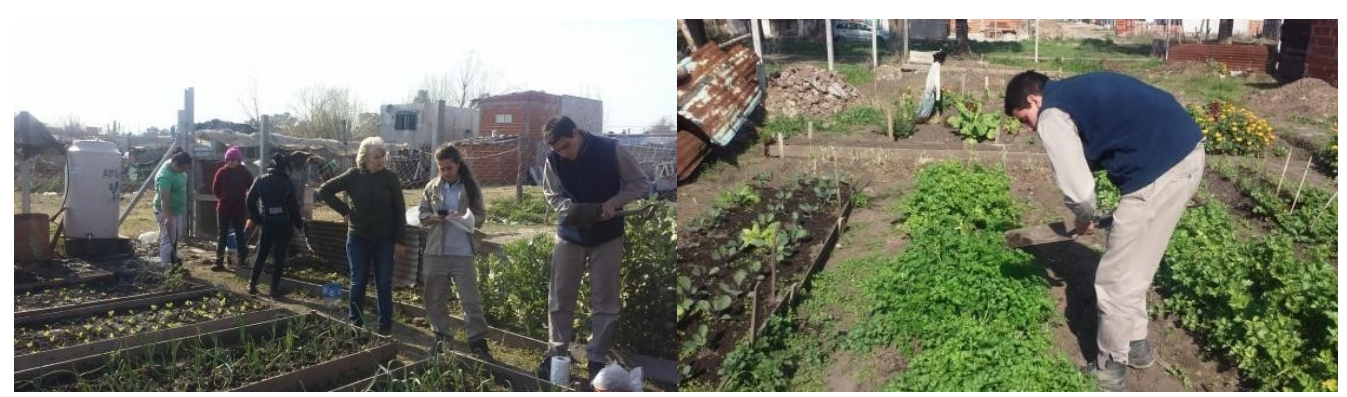

Figura 3. Instancia Práctica: Determinación de indicadores de calidad de suelo y muestreo de suelos y agua.

Durante el taller muchos huerteros tomaron nota, realizaron preguntas y expusieron sus opiniones mientras se desarrollaban los temas, en diálogo con las opiniones de docentes y alumnos, moderado por un docente a cargo. Se notó un mayor interés y participación en la temática de muestreo de suelos. Pensamos que esto se debe a que es algo que pueden hacer ellos sin necesidad de instrumental y es una práctica más popularizada entre los huerteros. Asimismo, en la instancia en el terreno mostraron mayor interés que en la instancia teórica, participando activamente con preguntas y aportando desde su experiencia como productores a medida que se realizaban las determinaciones. Es bien sabido que adquirir conocimientos desde la práctica, la vivencia personal y colectiva resulta en una mejor forma de aprendizaje (Hidalgo, 2016), por este motivo, y observando la respuesta de los huerteros, consideramos que esta actividad fue una de las más importantes tanto para el aprendizaje como para el vínculo e intercambio.

\section{Segundo taller}

Posteriormente se realizó un taller participativo que se llevó a cabo en el comedor del FOL "Oñondivepa" situado en el barrio "El Carmen" (Figura 4). Los participantes del taller fueron los mismos que en el taller anterior aunque hubo algunos vecinos y vecinas menos y otros nuevos que no habían asistido al primer taller. Pensamos que uno de los motivos de las ausencias fue la dificultad de traslado desde el otro barrio y que muchas son madres con niños que tenían que atender en el horario del taller.

En este taller se utilizó la técnica de sentarse en círculo, con un momento inicial de trabajo plenario en el que se fue elaborando de manera participativa un concepto general de suelo. Luego se hizo una instancia de trabajo en pequeños grupos, a cada grupo se le repartieron imágenes que hacían referencia al suelo y se dejó un tiempo para debatir cómo relacionar dichas imágenes con el suelo y por qué. Posteriormente cada grupo contó lo que discutió y se armó un debate plenario. Este fue coordinado por docentes y ayudantes de la FCA-UNLZ, quienes aportaban preguntas y comentarios para intentar comprender qué es el suelo y cómo se forma.

En este taller, en un principio, el interés pareció ser menor que en el anterior y sólo algunos pocos huerteros intervinieron más activamente. Sin embargo, una vez alcanzada cierta confianza, la participación aumentó y muchos socializaron sus conocimientos personales en cuanto a los sistemas agroecológicos, las actividades más importantes que realizan en las huertas comunitarias y los beneficios que mostraron las plantas aromáticas que habían traído de diferentes lugares. Asimismo, muchos manifestaron sus dudas respecto a algunos aspectos del suelo desconocidos, que se fueron respondiendo entre todos en el grupo.

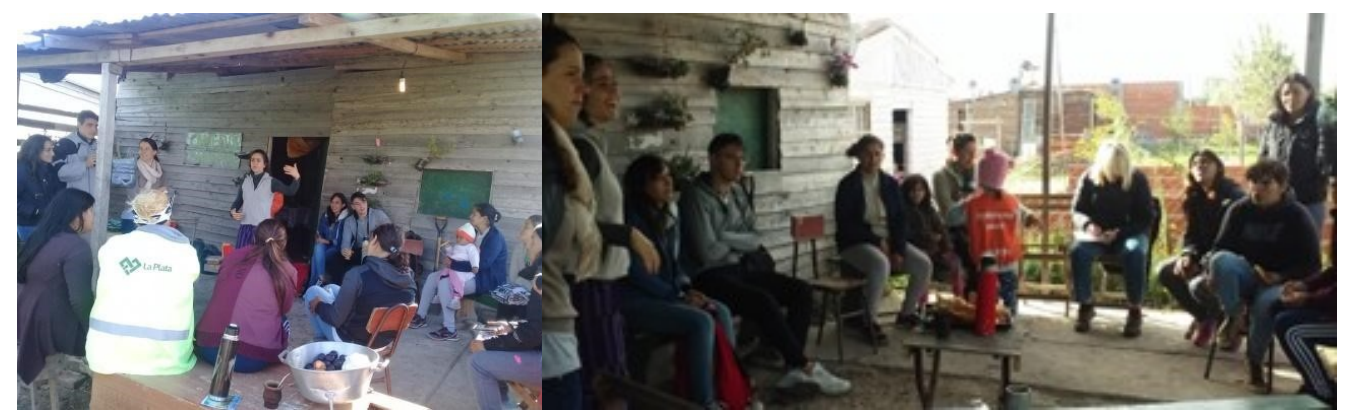

Figura 4. Taller participativo en el comedor Oñondivepa.

Luego se debatió de manera plenaria respecto de las funciones ecosistémicas del suelo y de la importancia del mismo en los sistemas hortícolas de producción agroecológica. Se notó que la mayoría de los huerteros per- 
cibía el valor del suelo en los sistemas de producción y la importancia de producir con un manejo que conserve dicho recurso. Además del interés detectado en los suelos, se mostraron interesados por conocer las características del agua. En este caso se ponen en juego sus conocimientos sobre un problema real y relevante en su vida (Vizcarro y Juárez, 2008) ya que en sus producciones, el agua es un recurso escaso en la época estival y resulta tener un gran impacto en la salud. A diferencia de la problemática de suelos, ellos vienen percibiendo las limitaciones respecto del agua desde hace un tiempo debido a que en ambos barrios se hicieron análisis de agua gracias al asesoramiento de técnicos de la Universidad Nacional de La Plata (UNLP) que cooperan con el FOL.

Para finalizar el taller se compartieron los resultados encontrados en las determinaciones a campo y en laboratorio, se diagnosticaron y se discutieron las problemáticas existentes de manera plenaria.

Con respecto al agua, los análisis mostraron en ambos barrios que los valores físico-químicos estaban dentro de los admitidos para consumo humano, no así los resultados bacteriológicos que mostraron desarrollo de bacterias Escherichia coli y Pseudomonas aeruginosa (datos no publicados). Estos resultados coinciden con análisis de agua anteriores realizados en los barrios por la UNLP. Los mismos vecinos y vecinas aseguran que la causa de esta problemática se relaciona con la precariedad del sistema de tuberías por donde llega y se distribuye el agua en los barrios. Las tuberías se apoyan sobre el margen de las veredas donde fácilmente pueden pincharse, facilitando el acceso de bacterias y otros contaminantes provenientes de las excretas de animales que circulan por las calles. Esta problemática suele formar parte del pliego reivindicatorio de la organización en los planes de lucha. Nuestra recomendación para subsanar el problema en lo inmediato, fue que hiervan el agua por más de un minuto y la consuman luego de que se haya enfriado o que agreguen dos gotas de lavandina por litro de agua y dejen reposar media hora (EPA, 2015).

En el suelo, las problemáticas más importantes detectadas fueron el $\mathrm{pH}$ elevado y el bajo contenido de carbono orgánico en el suelo (Paladino et al., 2019). Se hizo hincapié en cuáles son las posibles causas y consecuencias de las mismas, y cuáles serían las posibles medidas que deberían tomarse para mejorar la situación. Del debate plenario surgieron algunas propuestas como aumentar el agregado de compost domiciliario, agregar alguna enmienda orgánica agroecológica que tenga reacción ácida y agregar cal. También se sugirió contactarse con productores agroecológicos de zonas rurales para conocer sus problemáticas, compartir las propias y buscar soluciones en conjunto.

\section{Encuesta}

Al finalizar el último taller se entregó una encuesta a cada huertero. La misma se leyó de manera plenaria para garantizar su comprensión y se fue completando de forma individual. Se recolectaron 12 encuestas y las respuestas se procesaron mediante estadística descriptiva. A continuación, se detalla la encuesta realizada.

Seleccione lo que considere a su criterio:

1- Actividad que desarrolla en este espacio

TRADICIONAL TRANSICIÓN AGROECOLÓGICA

2- ¿Qué superficie posee en total?

Menos de 1 ha 1 a 5 ha 5 a 10 ha

3- ¿Tiene asesoramiento técnico?

$\mathrm{SI} \mathrm{NO}$

4-¿De dónde proviene el asesoramiento? INTA IPAF COOPERATIVA ESTADO UNIVERSIDAD

5- ¿Le interesa formarse sobre producción agroecológica?

6- ¿Los sistemas agroecológicos qué mejoras aporta?

ECONÓMICA RENDIMIENTO SALUD PRODUCTO SABROSO/NUTRITIVO AMBIENTAL

7-Hace cuántos años trabaja en agroecología hortícola urbana menos de $1 \quad \begin{array}{lll}1 \text { a } 3 & 3 \text { a } 5 & 5 \text { a } 10 \\ \text { más } 10\end{array}$

8- ¿Qué superficie realiza bajo este sistema?

TODA MITAD ALGUNA PARCELA

9- Existe interés sobre esta temática en su ámbito de trabajo NADA MUY POCO POCO MUCHO

10- De las prácticas y elementos mencionados abajo ¿Cuáles son los más necesarios para producir?

$\Delta$ Manejo integrado de plagas $\boldsymbol{\Delta}$ No agroquímios $\boldsymbol{\Delta}$ No insumo externo $\boldsymbol{\Delta}$ Corredor verde $\boldsymbol{\Delta}$ Compostaje

$\boldsymbol{\Delta}$ Control biológico $\boldsymbol{\Delta}$ Social compañerismo $\boldsymbol{\Delta}$ Rotación y asociación cultivos $\boldsymbol{\Delta}$ Soberanía alimentaria

$\Delta$ Bokashi $\Delta$ Alimentos saludables $\Delta$ Agrupaciones $\Delta$ Reciclaje de nutrientes $\Delta$ Productos de estación

$\Delta$ Cultivo de cobertura $\Delta$ Conocimiento huerteros $\Delta$ Observación a campo $\Delta$ Huerta pequeña superficie 
11-¿Qué insumos utiliza y de donde lo obtiene?

\begin{tabular}{|l|l|l|l|l|}
\hline & DONADO & PRODUCCIÓN PROPIA & PROHUERTA & COMPRADO \\
\hline Enmienda orgánica & & & & \\
\hline Semillas o plantines & & & & \\
\hline Fertilizante químico & & & & \\
\hline Agroquímicos & & & & \\
\hline Biopesticidas/biofertilizante & & & & \\
\hline
\end{tabular}

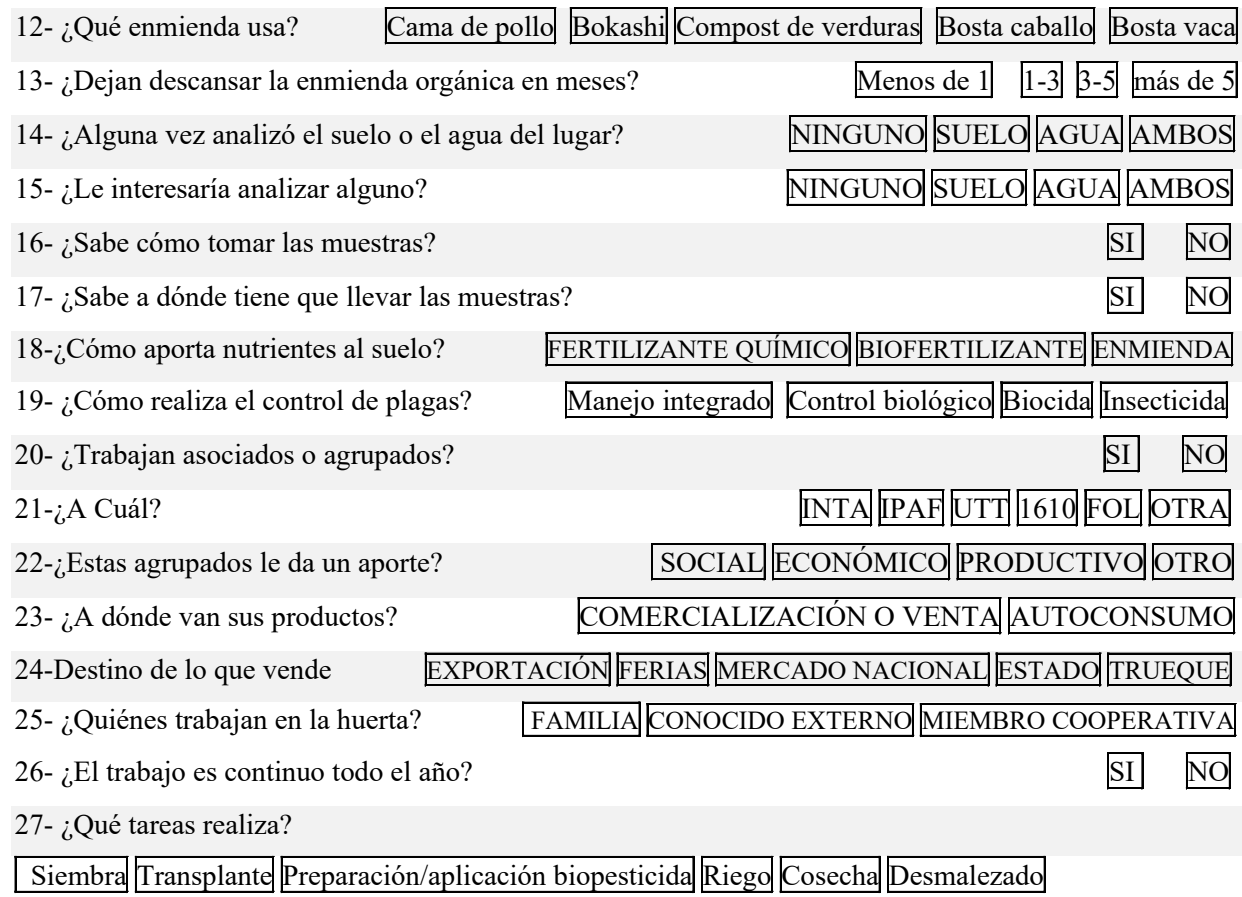

Según lo que respondieron los huerteros, la superficie total bajo horticultura urbana en la zona es de menos de 1 ha. En el caso de las huertas en "El Carmen" y "Altos de San Lorenzo" cuentan con asesoramiento técnico desde el FOL, con apoyo de la UNLP. Ellos trabajan agrupados, afirmando que el FOL es su forma de organización y que dicha organización en la mayoría de los casos, les otorga un beneficio social, económico y productivo (Figura 5). En este sentido, la percepción amplia respecto al beneficio que les otorga la organización, consideramos que se ancla en el carácter horizontal y asambleario del FOL. Además, esta respuesta da cuenta que la organización popular tiene que ver con otros aspectos de la vida, no solamente con lo económico, sino que atiende a otras cuestiones relacionadas a la vivienda, educación, género, salud, etc. Ellos mismos son los actores que desde el territorio enarbolan proyectos de largo plazo, entre los que se destaca la capacidad de producir y reproducir la vida, a la vez que establecen alianzas con otros sectores de las capas medias (Zibechi, 2003).

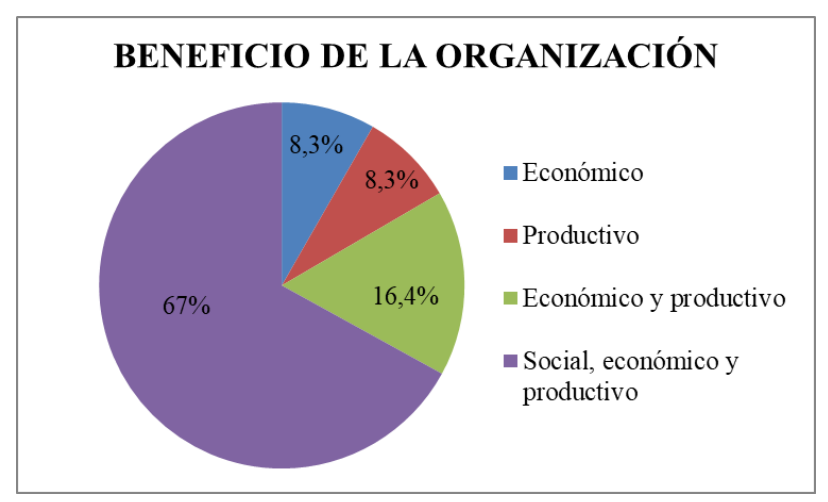

Figura 5. Porcentajes de respuesta a la pregunta: ¿Qué les proporciona la agrupación?. 
La mayoría de los huerteros trabaja en el lugar desde hace menos de 1 año (Figura 6). Esto puede deberse a que muchos realizan esta actividad en los momentos que se hayan desempleados tornándose una tarea de corto plazo o intermitente.

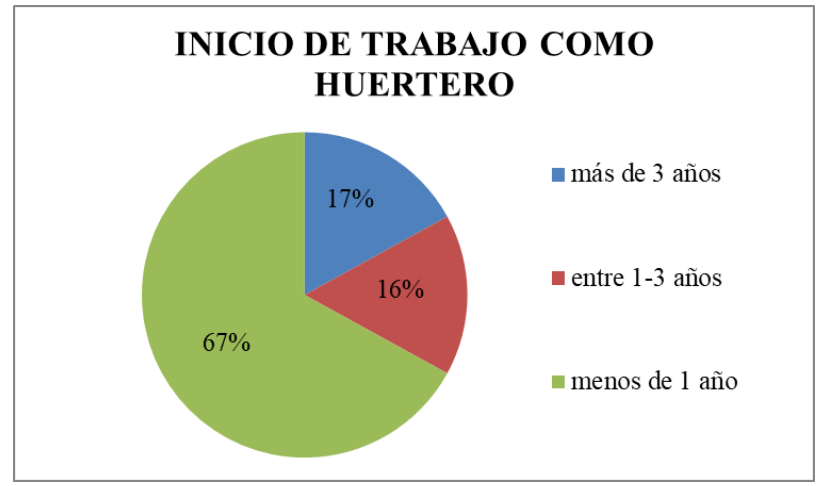

Figura 6. Porcentaje de respuesta a la pregunta ¿Cuántos años hace que trabaja en agroecología hortícola urbana?.

En la huerta trabajan los miembros de la cooperativa pero además cuentan con el apoyo de algún familiar o vecino por fuera de la cooperativa que suele ayudar. El trabajo es continuo a lo largo del año. El $50 \%$ de los encuestados realiza todas las actividades (siembra, trasplantes, preparación y aplicación de bioinsumos, cosecha, desmalezado y riego) y la otra mitad realiza alguna de las actividades desarrolladas a lo largo del ciclo. Toda la superficie que poseen se dedica al sistema bajo el cual dijeron que trabajan. En este sentido, se observaron respuestas encontradas en cuanto al sistema que desarrollan (Figura 7). Es esperable que no tengan claro el sistema con el cual producen dado que aun a nivel científico se discuten las definiciones y alcances de cada uno.

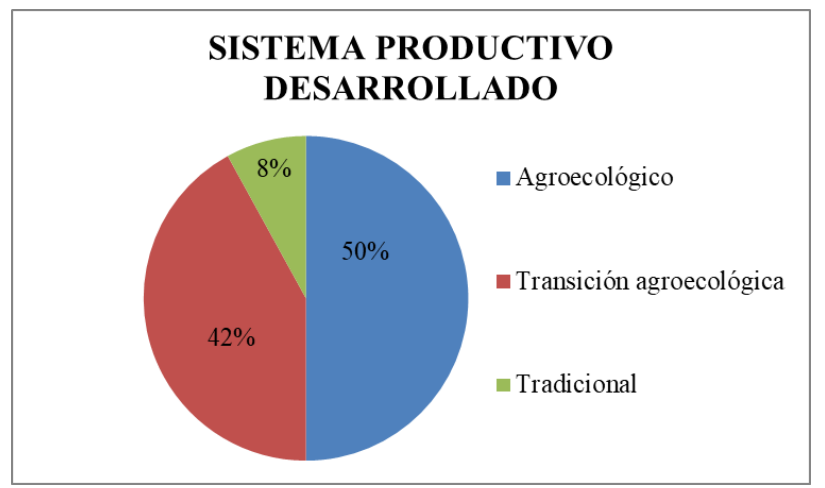

Figura 7. Porcentaje de respuesta a la pregunta: ¿Qué actividad desarrolla en el espacio?

Los huerteros afirmaron en la encuesta que la totalidad de los insumos que utilizan son donados o de producción propia. No se aplican fertilizantes químicos ni agroquímicos, sino que se producen biopestisidas o biofertilizantes. Al consultarles sobre la enmienda orgánica utilizada las respuestas variaron entre compostado de verduras y restos orgánicos, bosta caballo y vaca. Respecto al tiempo de compostaje del mismo, la mayoría respondió que lo dejan entre 3 a 5 meses y el resto que se composta entre 1 y 3 meses. Asimismo, en este trabajo se observó que el compost utilizado no siempre cumple con los tiempos de compostados y se debe mejorar la forma y distribución de las composteras. El compost generado por la propia comunidad o compostaje local es muy importante en sistemas agroecológicos pues permite el reciclaje de nutrientes (Altieri y Nicholls, 2000) pero su efecto sobre los cultivos o las propiedades del suelo dependerá de las características del mismo en función de la calidad del proceso de compostaje.

Por otro lado, todos (100\% de los encuestados) reconocen la importancia del análisis de agua y de suelo. Solo uno de los encuestados no responde, pero el $84 \%$ declara conocer cómo se toman las muestras y el $67 \%$ sabe a dónde se deben llevar para su análisis. Dado que la encuesta se realizó al finalizar los encuentros y observando estos porcentajes, podemos afirmar que los talleres contribuyeron a afianzar la valoración y el conocí- 
miento de los huerteros por el suelo y el agua. Es bien sabido que adquirir conocimientos desde la práctica, la vivencia personal y colectiva resulta en una mejor forma de aprendizaje (Barberá y Valdés 1996; Hidalgo, 2016).

Se observó también que a la totalidad de los encuestados le interesa mucho formarse en el tema de la agroecología. Uno de las consignas de la encuesta era identificar frases o manejos asociados a la agroecología o en transición agroecológica. En este punto más del 50 \% de los encuestados identificó las siguientes frases: "sin usar agroquímicos", "sin insumos externos", "social compañerismo", "alimentos saludables", "compostaje”, “observación a campo", "huerta en pequeñas superficies”, "corredor verde”, "control biológico", "rotación y asociación", "productos de estación". Para el resto de los casos las respuestas fueron variables. La falta de consenso respecto a la temática demuestra que se debe seguir profundizando sobre la agroecología, trasmitiendo conocimientos científicos que permitan conocer los beneficios que aporta esta forma de producir. Esto es importante y necesario ya que, los informes de International Assessment of Agricultural Knowledge, Science and Technology for Development (McIntyre et al., 2009) afirman que, para poder alimentar a nueve mil millones de personas esperadas en el año 2050, es necesario adoptar sistemas agrícolas más eficientes y recomiendan cambiar a la agroecología para impulsar la producción de alimentos y reducir la pobreza de la población.

Cuando se les preguntó por qué decidieron inclinarse hacia un sistema no tradicional de producción la mayoría respondió afirmativamente por los beneficios a nivel de la calidad del producto obtenido (Figura 8). Con esta respuesta los huerteros destacan la valoración de la alimentación saludable por sobre el rédito económico ya que mediante la producción en las huertas pueden acceder a alimentos frescos, sustituyendo los enlatados y carbohidratos refinados (Ibarra et al., 2018).

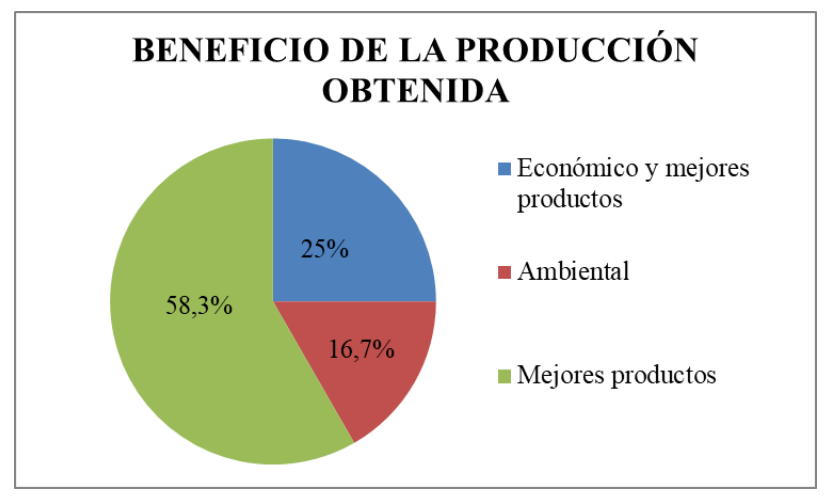

Figura 8. Porcentaje de respuestas a la pregunta: ¿Por qué decidieron trabajar con sistemas agroecológicos? El grupo "mejores productos" incluye alimentos más sabrosos, nutritivos y saludables.

Por otro lado, si bien la producción de alimentos sanos bajo un sistema agroecológico implica el cuidado del medio ambiente, cabe destacar que el beneficio ambiental de la producción obtenida es percibido por menos del 17\% de los encuestados. En este sentido, consideramos importante impulsar programas de extensión donde la educación ambiental adquiera mayor protagonismo. La educación ambiental es un proceso dinámico y participativo, cuyo objetivo es despertar en la población una conciencia que la haga identificarse con la problemática ambiental a escala mundial y local. Esta conciencia ambiental es un concepto multidimensional que busca identificar las relaciones de interacción e independencia que se dan entre el entorno y el ser humano, así como promover una relación entre ellos con el fin de garantizar el sostenimiento y calidad de las generaciones actuales y futuras (Jiménez Tello et al., 2015).

Respecto al destino de la producción, la mayoría de las respuestas afirman que lo producido queda en el barrio, predominando el autoconsumo y la venta dentro del mismo barrio, a vecinos que se encuentran por fuera de la organización (Figura 9). Esto coincide con lo reportado por Hernández (2006), quien informa que el destino más frecuente de la producción de la agricultura urbana es el autoconsumo. 


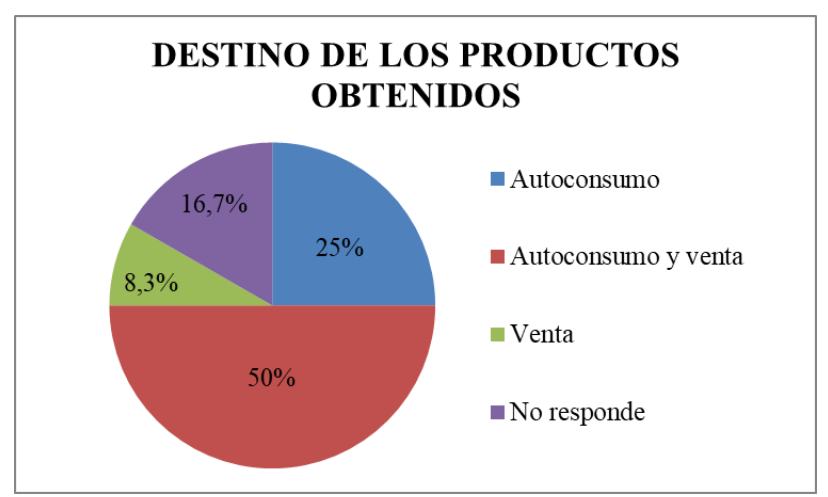

Figura 9. Porcentaje de respuesta a la pregunta: ¿A dónde van sus productos?.

De esta respuesta podemos deducir que la huerta comunitaria dentro de la organización no pretende ser un emprendimiento económico sino más bien un espacio donde construir la soberanía alimentaria. Es decir, ejercer el derecho de los pueblos de definir su propia alimentación y agricultura, asegurando el desarrollo sostenible (Windfuhr y Jonsén, 2005). En este sentido, la construcción de barrios autosustentables con una alimentación saludable y relaciones de intercambio virtuosas entre vecinos y vecinas, son los pilares que fundamentan el desarrollo de las huertas comunitarias del FOL (FOL, 2019).

Como cierre de la experiencia, se les entregó un informe final impreso con los resultados encontrados en las huertas, se compartió una merienda y se entregaron certificados de participación, uno por cada taller (Figura 10). Se entregó un total de 30 certificados, incluyendo docentes, alumnos y huerteros. Este momento resultó muy ameno y gratificante para muchos vecinos y vecinas quienes alegaban no haber recibido nunca antes en su vida ningún tipo de certificado, resultando en una motivación extrínseca para realizar la tarea (Anaya-Durand y Anaya-Huertas, 2010).

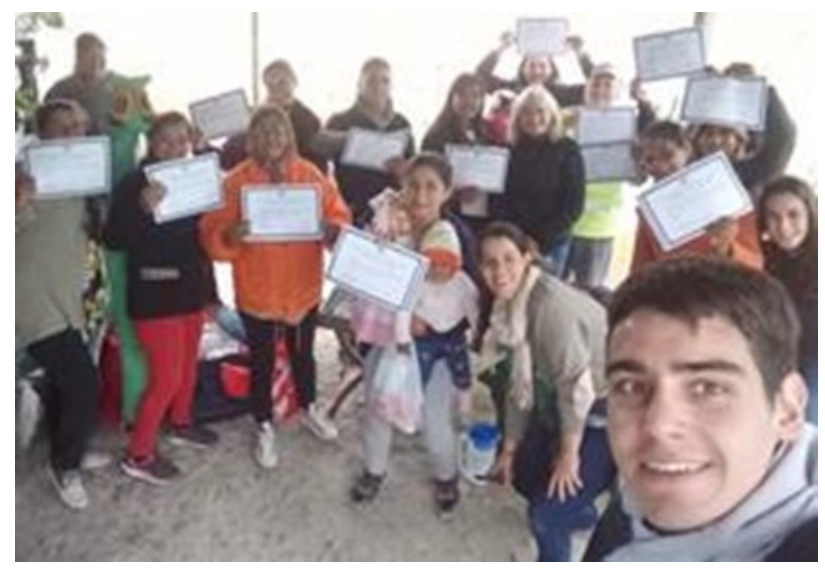

Figura 10. Fin de la experiencia. Merienda y entrega de certificados de participación.

\section{CONSIDERACIONES FINALES}

La experiencia de vinculación facilitó la generación de espacios de intercambio entre la comunidad educativa, que aportó los conocimientos académicos, y los huerteros quienes socializaron sus saberes empíricos. El trabajo en conjunto de estudiantes, docentes y huerteros, generó un espacio de mutuo conocimiento que contribuyó a su vez en la formación integral de todos y cada uno de los participantes. Los investigadores, docentes y estudiantes adquirieron conocimientos sobre el efecto de los sistemas agroecológicos sobre suelos antrópicos y sobre el trabajo comunitario en la producción hortícola. También, la experiencia sirvió para facilitar a la comunidad educativa el diagnóstico del estado del conocimiento científico de los huerteros respecto a la agroecología, medio ambiente y manejo de suelo y agua, poniendo en relieve las temáticas que requieren una mayor promoción en futuros programas de educación y extensión. Los huerteros aprendieron conocimientos académicos específicos del suelo y su manejo, desde la teoría y la práctica, y también pudieron afianzar sus conocimientos previos y la valoración de dicho recurso natural. Asimismo, esta experiencia permitió que tanto profesionales 
como estudiantes desarrollen competencias agronómicas al trabajar en un escenario de aprendizaje real, y competencias sociales al asumir un compromiso ético frente a situaciones de desigualdad social y baja calidad ambiental. A nivel institucional el acercamiento al territorio mediante los talleres no solo contribuyó en la generación de vínculos entre la universidad y organizaciones barriales sino que también permitió la vinculación con otras instituciones nacionales (INTA). De este modo, la universidad continúa manteniendo su rol activo como promotor del concepto de desarrollo local.

La experiencia también permitió caracterizar algunos suelos antrópicos en los barrios y evaluar el efecto de la agroecología sobre los mismos, lo cual no había sido analizado en el pasado. Asimismo, la experiencia facilitó la transferencia de los resultados encontrados en las determinaciones realizadas a campo y en laboratorio, además de la elaboración de un diagnóstico conjunto entre profesionales y huerteros de las problemáticas presentes respecto al suelo y al agua. De esta manera, mancomunadamente y potencializando ambos saberes se promovió, en un vínculo dialógico, la generación de propuestas de manejo consensuadas para mejorar los sistemas productivos existentes.

Por otro lado, la encuesta fue una herramienta útil para conocer los objetivos de la producción comunitaria en los barrios, para diagnosticar problemas y visibilizar las necesidades de los vecinos y vecinas que trabajan en las huertas, lo cual da el puntapié a la comunidad educativa para repensar futuras prácticas de extensión universitaria.

Uno de los mayores desafíos que se presentan hacia el futuro es aumentar la asistencia e intervención de los vecinos y vecinas. No todos los miembros de las cooperativas asistieron a los talleres lo cual podría relacionarse a dificultades de traslado, ocupación en otras tareas de mayor importancia o simplemente falta de interés. Asimismo, entre los presentes, solo los más activos, comentaban, opinaban y argumentaban. Esta dificultad se presentó en mayor medida al iniciar las reuniones, luego una vez generado un vínculo aumentó el interés por aprender y socializar sus conocimientos e inquietudes.

Finalmente, las relaciones que surgieron de este proyecto servirán para promover y fortalecer la vinculación de las organizaciones sociales del campo popular con las instituciones académicas y científicas. La vinculación universidad-cooperativas hortícolas, es importante ya que los huerteros organizados pueden tener más acceso a conocimientos científicos que les permitan mejorar sus condiciones de vida en sus territorios, a partir del empleo de buenas prácticas agrícolas. Asimismo, la aplicación de estas prácticas contribuye a mejorar la calidad de los alimentos generados y, en consecuencia, la calidad de vida de la población consumidora bajo la premisa del cuidado del ambiente mediante un manejo adecuado de los suelos.

\section{BIBLIOGRAFÍA}

Altieri, M y Nicholls, C.I. (2000). Agroecología. Teoría y práctica para una agricultura sustentable. Serie Textos Básicos para la Formación Ambiental (1era ed.). Programa de las Naciones Unidas para el Medio Ambiente, Red de Formación Ambiental para América Latina y Caribe, México.

Anaya-Durand, A. y Anaya-Huertas, C. (2010). ¿Motivar para aprobar o para aprender? Estrategias de motivación del aprendizaje para los estudiantes. Tecnología, Ciencia, Educación, 25(1):5-14 https:// www.redalyc.org/articulo.oa?id $=48215094002$

Barberá, O. y Valdés, P. (1996). El trabajo práctico en la enseñanza de las ciencias: una revisión. Enseñanza $\begin{array}{llllll}\text { de las } & \text { ciencias, } & 14 & \text { (3), } 365-379 . & \text { https://ddd.uab.cat/pub/ }\end{array}$ edlc/02124521v14n3/02124521v14n3p365.pdf

Chavarrías, M. (2005). Agricultura Urbana y Seguridad Alimentaría. Diario de la Seguridad Alimentaría.

Craul, P.J. (1999). Urban Soils: Applications and Practices. John Wiley \& Sons, Inc., New York.

De Kimpe, C.R. y Morel, J.L. (2000). Urban soil management: a growing concern. Soil Science 165:31-40.

EPA, Agencia de protección ambiental de Estados Unidos (2015). https://espanol.epa.gov/sites/productiones/files/2016-05/documents/spanish_emergency_disinfection_drinking_water_0.pdf Acceso 7 de agosto de 2020 .

FAO (1996). Análisis Mundial: Agricultura urbana, ¿una paradoja? En El Estado Mundial de la Agricultura y la Alimentación. Colección FAO: Agricultura, $\mathrm{N}^{\circ} 29 \mathrm{http} / / \mathrm{www}$.fao.org/3/w1358s/w1358s00.htm

Figueroa, J. e Izquierdo, J. (2002). Agricultura Urbana en la región Metropolitana de Santiago de Chile: Si- 
Paladino, I.R. et al.: Extensión universitaria en huertas comunitarias.

tuación de las Empresas Familiares Hidropónicas- estudios de casos. Santiago Chile. Oficina Regional de la FAO para América Latina y el Caribe. https:/www.redalyc.org/pdf/1932/193215872002.pdf

FOL Frente de Organizaciones en Lucha-Regionales (2019). Huertas agroecológicas en los barrios: una posibilidad para construir un ambiente sano. Nota en http://folweb.com.ar/nota/977/ huertas_agroecologicas_en_los_barrios_una_posibilidad_para_construir_un_ambiente_sano/. Acceso 25 de mayo de 2020.

Giuffré, L., Marbán, L.,Romaniuk, R., Vespasiano, C., Sammartino, F. y Arata, L. (2013). Diagnóstico edafológico para la planificación de huertas orgánicas familiares en suelos periurbanos. FAVE Sección Ciencias Agrarias, 12(1/2), 63-76. https://doi.org/10.14409/fa.v12i1/2.5119

Hernández, L. (2006). La agricultura urbana y caracterización de sus sistemas productivos y sociales, como vía para la seguridad alimentaria en nuestras ciudades. Cultivos Tropicales, 27(2):13-25.

Hidalgo, L.A. (2016). Arrojados en la acción. Aprender a enseñar en la experiencia de práctica profesional. Estudios Pedagógicos 42(4):11-30. http://dx.doi.org/10.4067/S0718-07052016000500002

Ibarra, J.T., Caviedes, J., Barreau, A. y Pessa, N. (2018). Huertas familiares y comunitarias: Cultivando soberanía alimentaria. Ediciones UC, 224 págs.

Jiménez Tello, M. J., Yebra-Rodríguez, Á. y Guerrero, F. (2015) Las bases de la Educación Ambiental. Iniciación a la investigación. Número extraordinario 6: Educación Ambiental y Discapacidad Intelectual. Tiempo para la inclusión socieducativa. Universidad de La Rioja, España. https:// dialnet.unirioja.es/ejemplar/416816.

Lal, R. y Stewart B.A. (2017). Urban Soils. Series: Advances in Soil Science. 406 págs.

McIntyre, B.D.; Herren, H.R.; Wakhungu, J.; Watson, R.T. (2009). Agriculture at a Crossroads: The Global Report. En IAASTD (The International Assessment of Agricultural Knowledge, Science and Technology for Development) Global Report. Synthesis Report; Island Press: Washington, DC, USA 608págs.

Paladino, I.R., Sokolowski, A.C., Wolski, J.E., Bregante, J., Visentini, J.V., Rodríguez, H., Rodríguez, E.P., Gagey, M.C.; De Grazia, J., Debelis, S. y Barrios, M.B. (2019). Efecto de la horticultura agroecológica sobre propiedades químicas de suelos urbanos del Gran La Plata. V Reunión Argentina de Geoquímica de Superficie, La Plata. http://sedici.unlp.edu.ar/handle/10915/77311

Pino, M. (2003). Estudio Post Doctoral Fitomejoramiento Participativo en la Agricultura Urbana de La Habana, Cuba. Programa AGROPOLIS, IDRC-Canadá.

Pereyra, F.X., Paladino, I.R., Villegas, D. y Patitucci, M. (2017). Nueva Propuesta de Clasificación de Suelos Urbanos en Zonas Antropizadas. Actas XX Congreso Geológico Argentino, Tucumán.

Poggi, M. (2016). Los talleres participativos y las mesas de trabajo: el testeo de estrategias participativas que reúnen capacidades cognitivas colectivas en la dimensionalidad de las variables. Actas V Encuentro Latinoamericano de Metodología de las Ciencias Sociales, Mendoza, Argentina. En Memoria Académica. http://www.memoria.fahce.unlp.edu.ar/trab_eventos/ev.8554/ev.8554.pdf.

Rodríguez Tarducci, R. (2018). Asentamientos informales en el Partido de La Plata. Una aproximación a las modalidades de ocupación del territorio. Estudios Socioterritoriales, 23: 119-136. http:// revistaest.wix.com/revistaestcig

Sarandón, S.J. y Flores, C.C. (2014). Agroecología: bases teóricas para el diseño y manejo de Agroecosistemas sustentables. Editorial de la UNLP

Urbes. (2005). Agricultura Urbana en el mundo. Acceso 2 de enero 2020. Disponible en: http:// www.ucf.edu.cu/URBES/CD/introduccion.html.

Vizcarro, C. y Juárez, E. (2008). ¿Qué es y cómo funciona el aprendizaje basado en problemas?. En J. García Sevilla (Comp.), El aprendizaje basado en problemas en la enseñanza universitaria (pp. 17-36). Murcia: Editum, Ediciones de la Universidad de Murcia.

Windfuhr, M. y Jonsén, J. (2005). Soberanía Alimentaria: Hacia la democracia en sistemas alimentarios locales. The Schumacher Centre for Technology and Development. ITDG Publishing. Reino Unido.

Zibechi, R. (2003). Los movimientos sociales latinoamericanos: tendencias y desafíos. OSAL, Observatorio Social de América Latina. http://www.pensamientocritico.org/rauzib1003.htm. 